\title{
Synthesis in Pilot Plant Scale and Physical Properties of Sulfonated Polystyrene
}

\author{
Cristiane R. Martins, Giacommo Ruggeri ${ }^{\#}$ and Marco-A. De Paoli ${ }^{*}$ \\ Instituto de Química, Universidade Estadual de Campinas, CP 6154, 13084-971 Campinas - SP, Brazil
}

\begin{abstract}
A sulfonação homogênea do poliestireno foi desenvolvida em escala pré-piloto produzindo polímeros com diferentes graus de sulfonação (18 a 22 mol \% de unidades estirênicas sulfonadas). O rendimento da reação depende principalmente da razão entre a concentração de sulfato de acetila e de poliestireno. As propriedades morfológicas e térmicas dos poliestirenos sulfonados, obtidas pela sulfonação homogênea, foram estudadas por microscopia eletrônica de varredura, calorimetria diferencial de varredura e termogravimetria. A temperatura de transição vítrea do poliestireno sulfonado aumenta em relação ao poliestireno puro e a $\Delta \mathrm{Cp}$ foi calculada a fim de confirmar as fortes interações com os grupos $\sim \mathrm{SO}_{3} \mathrm{H}$.
\end{abstract}

The homogenous sulfonation of polystyrene was developed in a pilot plant scale producing polymers with different sulfonation degrees (18 to 22 mole \% of sulfonated styrene units). The reaction yield depends chiefly on the concentration ratio of acetyl sulfate and polystyrene. The morphological and thermal properties of the sulfonated polystyrene obtained by homogeneous sulfonation were studied by means of scanning electron microscopy, differential scanning calorimetry and thermogravimetry. The glass transition temperature of sulfonated polystyrene increases in relation to pure polystyrene and $\Delta \mathrm{Cp}$ was evaluated in order to confirm the strong interactions among the $\sim \mathrm{SO}_{3} \mathrm{H}$ groups.

Keywords: sulfonation reaction, physical and thermal properties, polystyrene

\section{Introduction}

Sulfonation of polystyrene (PS) has been studied by a number of researchers, ${ }^{1-3}$ however, little detail is available in the literature about the sulfonation reactions and the thermal properties of the product. Sulfonation is defined as a substitution reaction used to attach the $\sim \mathrm{SO}_{3} \mathrm{H}$ group on the molecule of an organic compound via chemical bond to carbon or, less frequently, to a nitrogen atom of the organic compound. Generally, sulfonation of a polymer can be carried out as a heterogeneous reaction, i.e., the polymer and sulfonation agent exist in different phases, or as a homogeneous reaction in hydrocarbons or chlorinated solvents. ${ }^{4}$ Compounds, such as $\mathrm{H}_{2} \mathrm{SO}_{4}$ and $\mathrm{SO}_{3}$, are commonly used as sulfonating agents for various polymers, including polystyrene (PS).

The first studies on sulfonation of high polymers such as PS were published before World War II. Turbak ${ }^{2}$ sulfonated polystyrene in a homogeneous phase reacting

* e-mail: mdepaoli@iqm.unicamp.br

\# Present address: Dipartimento di Chimica e Chimica Industriale, Università di Pisa, Via Risorgimento 35, 56126, Pisa, Itália polystyrene with complexes of triethyl phosphate and sulfur trioxide as sulfonating agents in dichloroethane. Makowski et al. ${ }^{1}$ also prepared lightly sulfonated polystyrene by using acetyl sulfate complexes as sulfonation reagent in a solution of dichloroethane. In this reaction, random ionic functionalities along the polymer chains were generated without significant degradation or crosslinking of the reaction product. This homogeneous sulfonation method for PS is the one most frequently described in the literature.

Sulfonated ionomers ${ }^{4}$ were defined as macromolecular compounds containing the sulfonic group $\sim \mathrm{SO}_{3} \mathrm{H}$. Because of their interesting chemical and mechanical properties, these compounds are utilized satisfactorily, in a number of industrial applications, for example, for production of compatible blends of nonmiscible polymers, ion exchange materials, membranes for reverse osmosis and ultrafiltration, plasticizers for macro-defect-free concretes and conductive composites. ${ }^{5}$ Generally, the sulfonation of high polymers as a method for the preparation of sulfonated ionomers displays the following basic features: $(i)$ a random distribution of inserted $\sim \mathrm{SO}_{3} \mathrm{H}$ groups along the PS chain; (ii) a minimum of chain-to-chain heterogeneity; (iii) the 
sulfonation proceeds without any significant polymer degradation and $(i v)$ the characterization of sulfonated polystyrene (PS-SO ${ }_{3} \mathrm{H}$ ) can be simplified by using polymers with narrow molar mass distributions. ${ }^{4}$ Ever since, the utilization of sulfonated polymers has been growing in various industrial, domestic and medical applications.

The sulfonation of polystyrene with sulfonic acid groups has been also demonstrated to be an effective route to compatibilize polystyrene with various nitrogen -containing polymers (for example, polyamides and conducting polymers as polyaniline). ${ }^{6,7}$ In these cases it was observed that, during the melt blending, the addition of $\mathrm{PS}_{-} \mathrm{SO}_{3} \mathrm{H}$ to the polymers leads to a torque rise because of strong chain to chain interactions. Furthermore, the torque profiles of pure $\mathrm{PS}-\mathrm{SO}_{3} \mathrm{H}$ materials cannot be obtained, since these materials crosslink at high temperatures. ${ }^{6}$

Although numerous references are given to the patent of Makowski et al., ${ }^{1}$ that patent does not give enough details about the experimental procedure adopted. In this work, we describe the reactions, thermal and physical properties and the interactions present in the sulfonated polystyrene, as compared to pure PS. Discussion on crosslinking of $\mathrm{PS}-\mathrm{SO}_{3} \mathrm{H}$ is also included.

\section{Experimental}

\section{Materials}

The starting polymer was an atactic PS (Piramidal Termoplásticos) with $\bar{M}_{n}=33000 \mathrm{~g} \mathrm{~mol}^{-1}$ and $\bar{M}_{w} / \bar{M}_{n}=$ 4.9, used as received. Sulfuric acid (95-97\%, Merck), acetic anhydride (Synth, p.a.), dichloromethane (Synth, p.a.), 2propanol (Synth, p.a.), NaOH (Vetec), methanol (Synth, p.a.) and $\mathrm{KHC}_{8} \mathrm{H}_{4} \mathrm{O}_{4}$ (Qeel, p.a.) were used as received.

\section{Homogeneous sulfonation of PS}

Polystyrene was sulfonated in $\mathrm{CH}_{2} \mathrm{Cl}_{2}$ at $40{ }^{\circ} \mathrm{C}$ with acetyl sulfate according to our patented procedure. ${ }^{8}$ This new procedure is similar to that patented by Makowski et $a l .{ }^{1}$ to obtain sulfonated polystyrene. The difference resides in the solubilization step of the amorphous thermoplastic with a different solvent. In our method the synthesis was carried out on a pilot plant scale, using milder conditions and thus lowering energy consumption.

The main steps for the homogeneous sulfonation were:

Acetyl sulfate solution preparation. This solution was prepared by mixing a fixed amount of dichloromethane and acetic anhydride under inert atmosphere $\left(\mathrm{N}_{2}\right)$. The solution was cooled to $0{ }^{\circ} \mathrm{C}$ and $95-97 \%$ sulfuric acid was carefully added. This reaction mixture (Figure 1a) was stirred until a homogeneous and clear solution was obtained at room temperature. During the preparation, an excess of acetic anhydride was used to scavenge any trace of water, if present. The acetyl sulfate was freshly prepared prior to each sulfonation reaction.

Sulfonation reaction. Different amounts of PS were dissolved in $\mathrm{CH}_{2} \mathrm{Cl}_{2}$ (different volumes) in a three-neck round-bottomed flask (6 L) equipped with mechanical stirring, thermometer and separator funnel. The flask containing the solution was heated to $40{ }^{\circ} \mathrm{C}$ in order to obtain total solubilization of PS and purged with $\mathrm{N}_{2}$ for 30 min. A freshly prepared acetyl sulfate solution was added using the separator funnel. The reaction mixture (Figure 1b) was maintained at $40{ }^{\circ} \mathrm{C}$ under stirring for $2 \mathrm{~h}$. The solution became clear yellow after adding the sulfonating agent. The reaction was interrupted by adding an excess of 2-propanol for $30 \mathrm{~min}$ and cooling to room temperature. Finally, the sulfonated polymer was isolated.

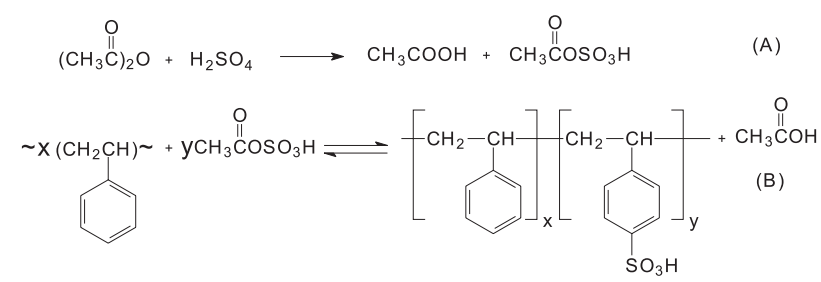

Figure 1. Reaction scheme of homogeneous sulfonation: (A) acetysulfate generation and (B) sulfonation of PS.

$\mathrm{PS}-\mathrm{SO}_{3} \mathrm{H}$ isolation. The method of isolating of $\mathrm{PS}-\mathrm{SO}_{3} \mathrm{H}$ was dependent on the sulfonation level, see Table 1. The PS- $\mathrm{SO}_{3} \mathrm{H}$ was precipitated by dripping the preparation solution into a large volume of boiling water, followed by washing several times with water (to eliminate the solvent and hydrolyze the acetyl sulfate). After, the product was filtered and dried under vacuum up to constant weight. The PS- $\mathrm{SO}_{3} \mathrm{H}$ was stored in a desiccator containing $\mathrm{CaCl}_{2}$, due to its extremely hygroscopic nature.

Sulfonation level determination. The sulfonation level of $\mathrm{PS}-\mathrm{SO}_{3} \mathrm{H}$ samples was determined by titration with a standard $0.01 \mathrm{~mol} \mathrm{~L}^{-1} \mathrm{NaOH}$ solution in methanol. All titrations were carried out by dissolving $150 \mathrm{mg}$ of PS$\mathrm{SO}_{3} \mathrm{H}$ in $15 \mathrm{~mL}$ of methanol. The sulfonation degree $(\mathrm{x})$ is expressed as mole percent of the sulfonated styrene repeating units, $\mathrm{PS}_{-\mathrm{xSO}} \mathrm{H}$. (Table 1).

\section{Characterization of sulfonated polystyrene}

Infrared spectra were recorded using a Perkin-Elmer FT-IR 1600 spectrophotometer. PS was analyzed as compression molded film and $\mathrm{PS}-\mathrm{SO}_{3} \mathrm{H}$ samples were measured as $\mathrm{KBr}$ pellets. Sixty-four scans were taken with 
Table 1. Results of the homogeneous sulfonation of PS

\begin{tabular}{|c|c|c|c|c|}
\hline Samples & $\begin{array}{r}\mathrm{x}-\mathrm{SO}_{3} \mathrm{H} \\
(\mathrm{mol} \%)^{\mathrm{a}}\end{array}$ & $\begin{array}{l}\text { Acetysulphate } \\
\text { solution }(\mathrm{mL})\end{array}$ & $\begin{array}{l}\text { Final } \\
\text { product }(\mathrm{g})\end{array}$ & $\begin{array}{l}\text { Yield } \\
(\%)\end{array}$ \\
\hline $\mathrm{PS}-\mathrm{SO}_{3} \mathrm{H}$ & 15.0 & 15.0 & 32.0 & 95.0 \\
\hline $\mathrm{PS}-\mathrm{SO}_{3} \mathrm{H}$ & 18.0 & 45.0 & 44.0 & 65.0 \\
\hline $\mathrm{PS}-\mathrm{SO}_{3} \mathrm{H}$ & 40.0 & 20.0 & 12.0 & 42.0 \\
\hline $\mathrm{PS}-\mathrm{SO}_{3} \mathrm{H}$ & 19.7 & 275.8 & 297.0 & 73.0 \\
\hline $\mathrm{PS}-\mathrm{SO}_{3} \mathrm{H}$ & 21.0 & 275.8 & 396.0 & 91.0 \\
\hline $\mathrm{PS}-\mathrm{SO}_{3} \mathrm{H}$ & 22.0 & 275.8 & 415.0 & 97.0 \\
\hline
\end{tabular}

${ }^{a} \mathrm{x}=$ sulfonation degree.

a resolution of $2 \mathrm{~cm}^{-1}$. The FT-IR spectra were used to qualitatively characterize the $\sim \mathrm{SO}_{3} \mathrm{H}$ groups.

Thermal stability of PS and PS- $\mathrm{SO}_{3} \mathrm{H}$ was studied by thermogravimetry (TGA) using a DuPont 951 thermal analyzer, from $25^{\circ} \mathrm{C}$ to $500{ }^{\circ} \mathrm{C}$ (heating rate of $10^{\circ} \mathrm{C} \mathrm{min}^{-1}$ ) under argon atmosphere with approximately $10 \mathrm{mg}$ of sample. All samples were previously heated to $100{ }^{\circ} \mathrm{C}$ for 5 min to eliminate residual water (humidity).

Differential Scanning Calorimetry (DSC) measurements were performed in a TA Instruments 2100 analyzer from 30 to $250{ }^{\circ} \mathrm{C}$, at $10{ }^{\circ} \mathrm{C} \mathrm{min}^{-1}$, under $\mathrm{N}_{2}$ and using approximately $10 \mathrm{mg}$ of sample. All samples were submitted to a first heating ( 30 to $250^{\circ} \mathrm{C}$ ) followed by an isotherm for $5 \mathrm{~min}$ at $250{ }^{\circ} \mathrm{C}$, cooling to $30^{\circ} \mathrm{C}$, isotherm for 5 min at $30^{\circ} \mathrm{C}$ and a second heating cycle $\left(30\right.$ to $\left.250{ }^{\circ} \mathrm{C}\right)$, to evaluate the irreversible transitions.

The surface morphology of the $\mathrm{PS}-\mathrm{SO}_{3} \mathrm{H}$ powder and the $\mathrm{PS}_{-} \mathrm{SO}_{3} \mathrm{H}$ compression molded films was studied in a scanning electron microscope (SEM) in JEOL Model JSM $\mathrm{T}-300$ equipment, operating at $20 \mathrm{kV}$. The film was also fractured under liquid nitrogen to record the features of the fracture surface. The samples were gold-sputtered prior to measurements.

Wide-angle X-ray diffraction measurements were carried out using a Shimadzu XD-3A and filtered $\mathrm{CuK} \alpha$ radiation. The diffractometer was operated at $40 \mathrm{kV}$ and $30 \mathrm{~mA}$. The diffraction patterns of $\mathrm{PS}$ and $\mathrm{PS}-\mathrm{SO}_{3} \mathrm{H}$ powders were obtained by scanning the samples in an interval of $2 \theta$ from 5 to 50 degrees, at a rate of 1.0 degree $\mathrm{s}^{-1}$.

\section{Results and Discussion}

\section{Sulfonation reaction}

Small-scale laboratory bench synthesis was carried out prior to pilot plant scale synthesis. To scale-up the sulfonation reaction, the amount of reagents and their solutions were increased proportionally to the volume of the reaction vessel. The reactions involved in the homogeneous sulfonation of PS are shown in Figure 1.
The sulfonation reaction could be also accompanied with the sulfone formation by following crosslinking reaction between two sulfonic groups of different $\mathrm{PS}_{-} \mathrm{SO}_{3} \mathrm{H}$ units either by intermacromolecular or by intramacromolecular mechanism. The most probable crosslinking reaction mechanism is shown in Figure 2. The tendency to crosslinking reaction is probably increased by increasing the content of sulfonic groups, by increasing the concentration of the sulfonating agent in polymer solution and also by increasing the reaction temperature. Previous studies $^{9}$ revealed that yields near $30 \%$ of sulfone were obtained for reactions at a temperature range from 70 to $80^{\circ} \mathrm{C}$ and the sulfone content arises to ca. $50 \%$, when reaction was carried out within the interval from 150 to $200^{\circ} \mathrm{C}$. The sulfone yield was reduced by sulfonation with liquid $\mathrm{SO}_{3}$ at about $-10^{\circ} \mathrm{C}$, or by addition of acetic acid. ${ }^{9}$

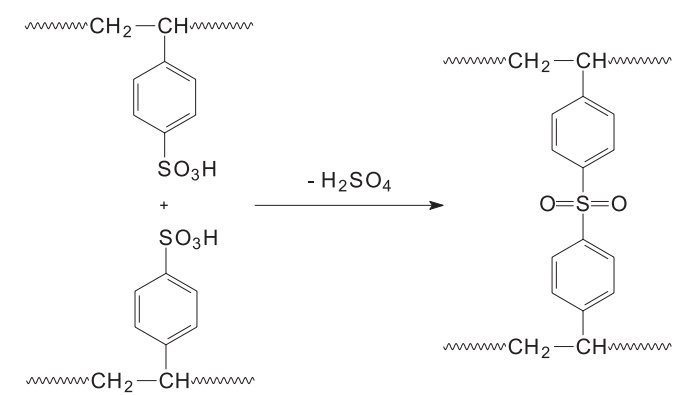

Figure 2. Crosslinking reaction of $\mathrm{PS}-\mathrm{SO}_{3} \mathrm{H}$.

The sulfonation degrees achieved are listed in Table 1. For sulfonation level near 15 mole \%, no problems were found to isolate the polymer. At sulfonation degrees higher than 30 mole $\%$, in our case PS- $40.0 \mathrm{SO}_{3} \mathrm{H}$, a high solubility in water was observed and the polymer was isolated after evaporating the organic solvent and precipitated by stirring after treatment of the aqueous solution with a large amount of $\mathrm{NaCl}$. In the case of the samples obtained with other sulfonation degrees (18 to 22 mole \%), a fine dispersion in water was obtained, that could be separated by a time-consuming filtration.

\section{FT-IR characterization}

The FT-IR spectra of $\mathrm{PS}_{-} \mathrm{SO}_{3} \mathrm{H}$ powders were taken over the range of wavenumbers from 400 to $4000 \mathrm{~cm}^{-1}$, but for the analysis of sulfonic groups, spectra are shown over the range from 800 and $1400 \mathrm{~cm}^{-1}$ (Figure 3). Sulfonic group vibration bands are reported at approximately 1040 and $1180 \mathrm{~cm}^{-1}{ }^{4}$. Kucera et al ${ }^{9}$ have studied the characteristic infrared absorbances for $\mathrm{PS}-\mathrm{SO}_{3} \mathrm{H}$ and suggested the bonding of the sulfonic groups to the aromatic ring of PS 
(out of plane deformation bands assigned to substituted aromatic ring $\gamma\left(\mathrm{C}_{\mathrm{ar}}-\mathrm{H}\right)$ at wavenumbers approximately from 830 to $\left.850 \mathrm{~cm}^{-1}\right)$. The absorption at $1040 \mathrm{~cm}^{-1}$ results from the symmetric stretching vibration of $\mathrm{SO}_{3} \mathrm{H}$ groups and the absorption at $1127 \mathrm{~cm}^{-1}$ results from a sulfonate anion attached to a phenyl ring. Our results are in agreement with the literature ones. ${ }^{9,10}$ We verified that the $v_{\text {as }}(\mathrm{S}-\mathrm{O})$ vibration at $1180 \mathrm{~cm}^{-1}$ appears as a very broad band at approximately $1100 \mathrm{~cm}^{-1}-1350 \mathrm{~cm}^{-1}$. The arrows denote the positions of the major sulfonate absorption bands in the FTIR spectra of the sulfonated polymers.

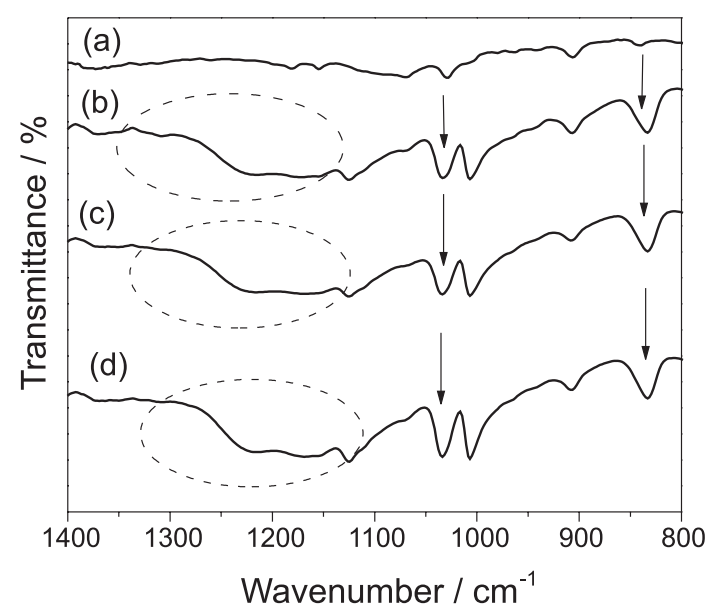

Figure 3. Infrared spectra of (a) PS, (b) $\mathrm{PS}-18.0 \mathrm{SO}_{3} \mathrm{H}$, (c) PS$40.0 \mathrm{SO}_{3} \mathrm{H}$ and (d) $\mathrm{PS}-22.0 \mathrm{SO}_{3} \mathrm{H}$. The arrows designate the absorbances due to sulfonation.

\section{Thermal properties}

Thermal stability of PS and PS-SO $\mathrm{S}_{3} \mathrm{H}$ was studied under argon atmosphere by TGA. This analysis shows that a decrease in thermal stability occurs for sulfonated polystyrene as a function of sulfonic groups concentration, as compared to PS. Pure PS shows a weight loss process with its onset at approximately $350{ }^{\circ} \mathrm{C}$. Sulfonated polystyrene shows weight loss starting at $200{ }^{\circ} \mathrm{C}$ (Figure $4 a)$. In Figure $4 b$ the degradation process in a single step for PS-SO $\mathrm{SO}_{3} \mathrm{H}$ is better visualized. Similar results were found for samples with the other sulfonation degrees. However, this stability decrease does not affect the use of PS-SO $\mathrm{S}_{3} \mathrm{H}$ in melt blending with others polymers, since this is usually carried out at temperatures lower than $180^{\circ} \mathrm{C}$.

The DSC curves for PS and PS-SO $\mathrm{H}_{3}$ are shown in Figure 5. Both samples of $\mathrm{PS}-\mathrm{SO}_{3} \mathrm{H}$ present an endothermic peak at $130{ }^{\circ} \mathrm{C}$ in the first heating run, which could be assigned to the presence of the sulfonated groups in the polymer chains. As expected, they cannot be assigned to crystalline melting because $\mathrm{X}$-ray diffraction analysis indicates that
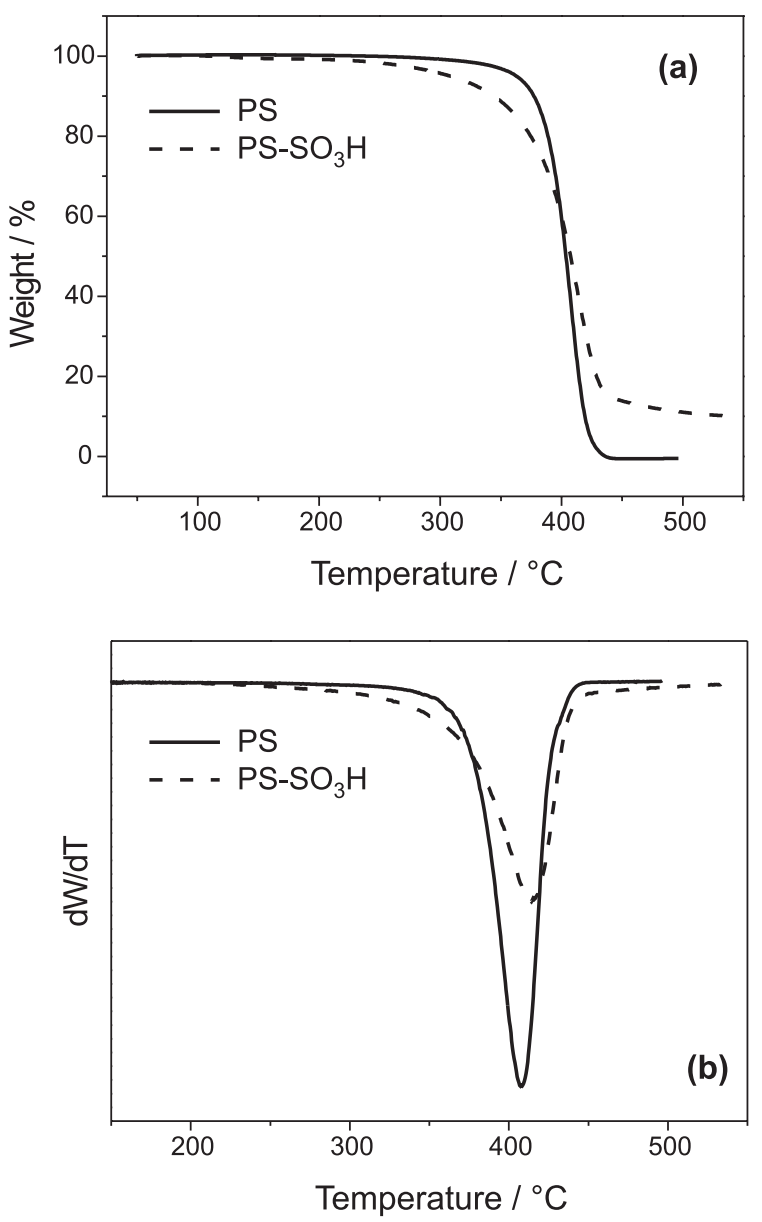

Figure 4. (a) Thermogravimetic curves $\left(10{ }^{\circ} \mathrm{C} \mathrm{min}^{-1}\right.$, argon) for PS and PS-22.0 $\mathrm{SO}_{3} \mathrm{H}$ and (b) DTG curves of samples.

both $\mathrm{PS}-\mathrm{SO}_{3} \mathrm{H}$ samples are amorphous (Figure 6). This behavior cannot be assigned to the melting of pure PS either, because PS is also amorphous. These transitions are irreversible, as shown in Figures 5a and 5b for the second heating run. In contrast, the glass transition temperatures of $\mathrm{PS}-\mathrm{SO}_{3} \mathrm{H}$ are shifted to higher temperatures, as compared to pure PS (from 100 to $140{ }^{\circ} \mathrm{C}$ ). In this case, to elucidate this phenomenon we evaluated the variation of heat capacity ( $\Delta \mathrm{Cp}$, Table 2 ). The decrease of $\Delta \mathrm{Cp}$ observed during glass transition for these samples can be considered as an indicator of the increase of structural rigidity of the materials as a function of the increase of the amount of sulfonic groups. ${ }^{11}$

\section{Morphological characterization}

The SEM micrographs of sample PS-22.0 $\mathrm{SO}_{3} \mathrm{H}$ are reported in Figure 7. These Figures clearly show that, even after extensive functionalization reaction, PS maintains its characteristic morphology of thermoplastic amorphous 

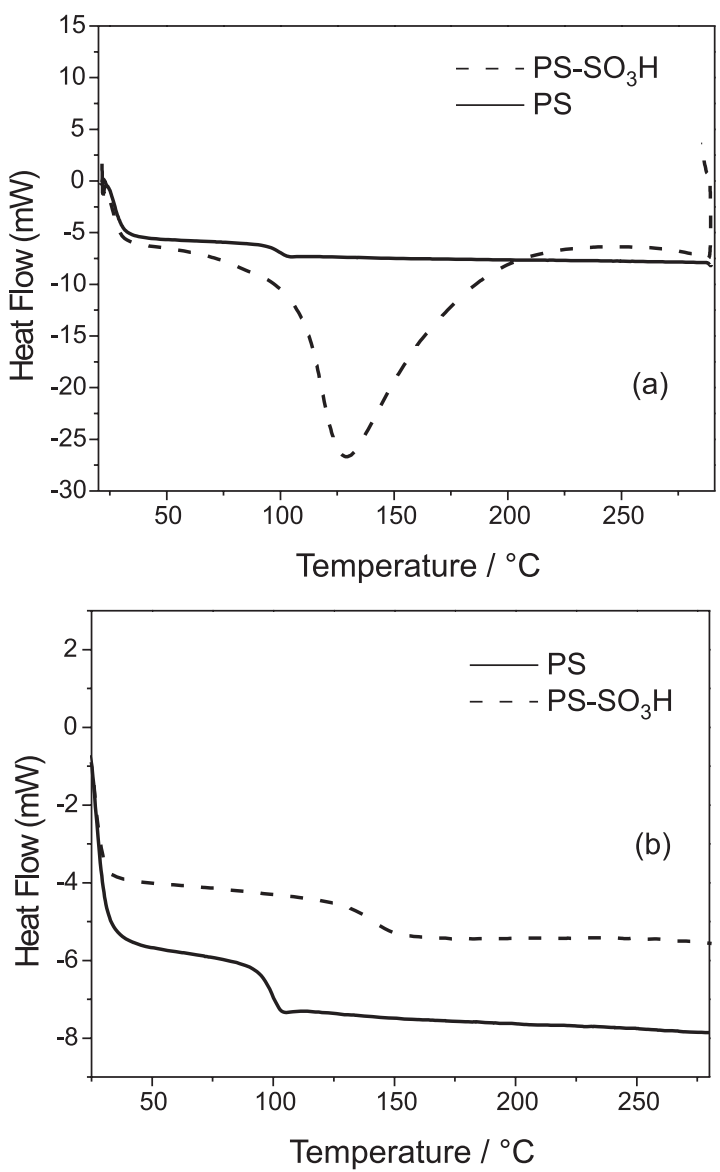

Figure 5. DSC curves for PS and PS-22.0SO3H: (a) first heating run and (b) second heating run.

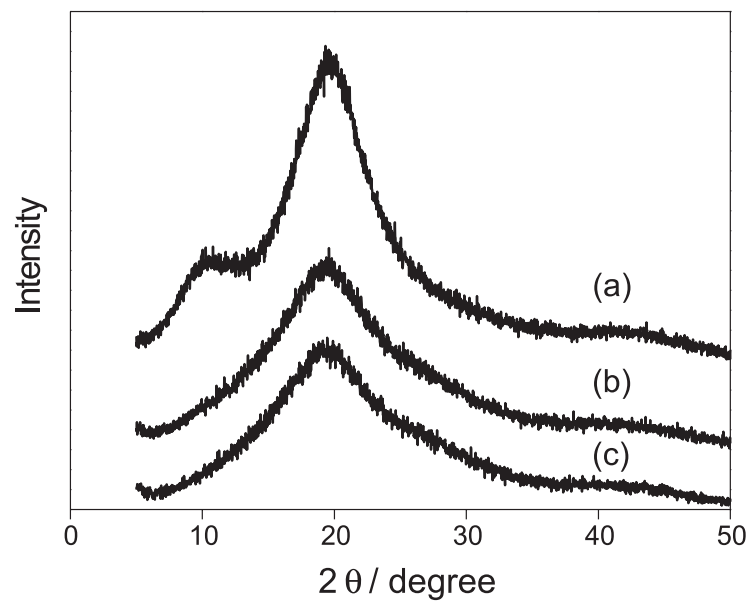

Figure 6. X-ray diffraction patterns of pure PS (a) and (b) PS$22.0 \mathrm{SO}_{3} \mathrm{H}$ and (c) $\mathrm{PS}-19.7 \mathrm{SO}_{3} \mathrm{H}$.

polymer. The PS-22.0 $\mathrm{SO}_{3} \mathrm{H}$ sample powder micrograph (Figure 7a), and fracture surface micrograph (Figure 7c), are typical of a brittle and glassy material. In addition, the surface texture (Figure 7b) is characterized by the presence
Table 2. DSC results for PS and PS-21.0SO $\mathrm{S}_{3} \mathrm{H}$ samples

\begin{tabular}{lrccc}
\hline Samples & $\operatorname{Tg}^{\mathrm{a} /}{ }^{\circ} \mathrm{C}$ & $\begin{array}{c}\mathrm{C}_{\mathrm{p}}\left(\text { below }^{\mathrm{b}}\right) / \\
\left(\mathrm{J} / \mathrm{g}{ }^{\circ} \mathrm{C}^{-1}\right)\end{array}$ & $\begin{array}{c}\mathrm{C}_{\mathrm{p}}\left(\mathrm{after}^{\mathrm{b}}\right) / \\
\left(\mathrm{J} / \mathrm{g}{ }^{\circ} \mathrm{C}^{-1}\right)\end{array}$ & $\begin{array}{c}\Delta \mathrm{C}_{\mathrm{p}}{ }^{\mathrm{a}} \\
\left(\mathrm{J} / \mathrm{g}{ }^{\circ} \mathrm{C}^{-1}\right)\end{array}$ \\
\hline PS & 98.44 & 1.17 & 1.93 & 0.33 \\
PS-21.0 & 139.70 & 0.87 & 1.51 & 0.28 \\
\hline
\end{tabular}

a calculated at second heating run (DSC curve); ${ }^{\mathrm{b}}$ calculated from heat flow below and after glass transition according to ASTM E 1269-95.

(a)

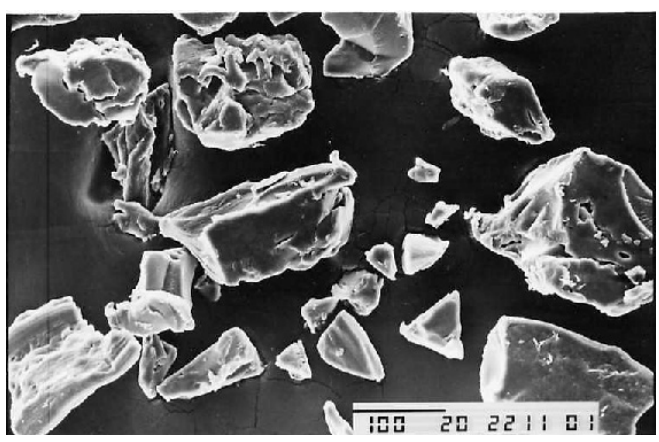

(b)

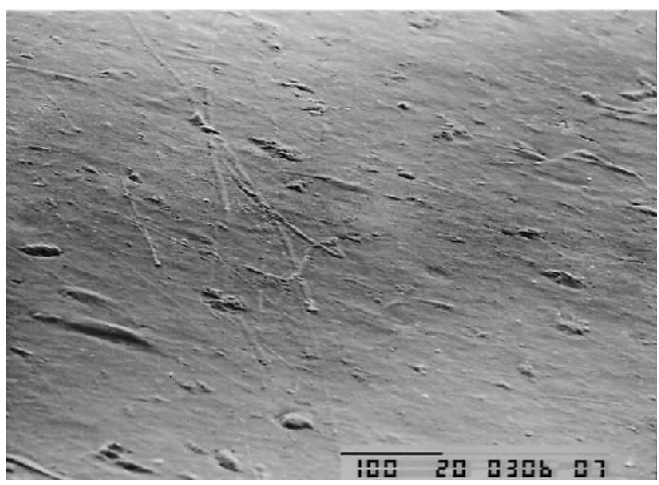

(c)

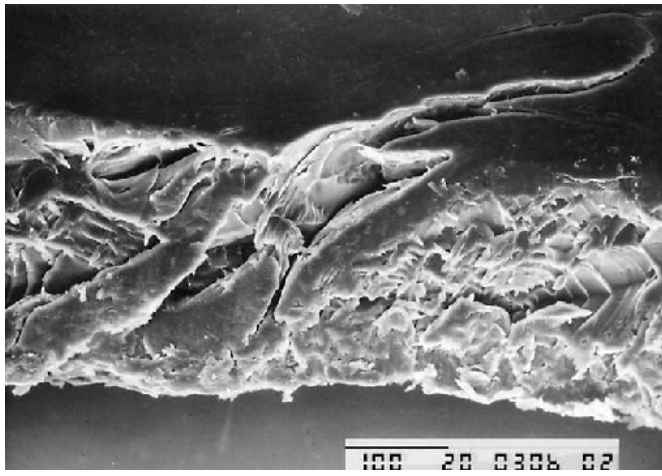

Figure 7. SEM micrographs of (a) powder PS-22.0 $\mathrm{SO}_{3} \mathrm{H}$, (b) film $\mathrm{PS}-22.0 \mathrm{SO}_{3} \mathrm{H}$ and (c) fractured film PS- $22.0 \mathrm{SO}_{3} \mathrm{H}$.

of imperfections, probably due to the presence of aggregates of sulfonic groups at the film surface.

\section{Conclusions}

Polystyrene is relatively easy to functionalize with sulfonic acid groups to produce sulfonated polystyrene 
containing up to $20 \mathrm{~mol} \%$ of sulfonic groups. The sulfonation reaction in a pilot plant scale, using mild conditions, was possible and allowed obtaining $\mathrm{PS}-\mathrm{SO}_{3} \mathrm{H}$ without problems to isolate the polymer. The sulfonation level is controlled by the ratio of acetyl sulfate and PS in the reaction mixture. The thermal stability of the sulfonated polymer allows its use for processing blends by melt extrusion.

\section{Acknowledgements}

C.M.R. and G.R. are grateful to FAPESP for fellowships (98/12558-4 and 98/1960-6). The authors also thank Piramidal Termoplásticos Ltda for the PS sample and J. A. S. da Silva for helping in the pilot plant laboratory.

\section{References}

1. Makowski, H.S.; Lundberg, R.D.; Singhal, G.H.; US pat. 3,870, 841, 1975.
2. Turbak, A. F.; Ind. Eng. Chem., Prod. Res. Dev. 1962, 1, 275.

3. Kucera, F.; Jancar, J.; Chem. Papers 1996, 50, 224.

4. Kucera, F.; Jancar, J.; Polym. Eng. Sci. 1998, 38, 783.

5. Fu, Y.; Weiss, R.A.; Synth. Met. 1997, 84, 103.

6. Molnár, A.; Eisenberg, A.; Polym. Eng. Sci. 1992, 32, 1665.

7. Martins, C.R.; Ph.D. Thesis, Universidade Estadual de Campinas, Brazil, 2002.

8. Martins C.R.; De Paoli, M-A.; Br PI 101700-4, 2001.

9. Kucera, F.; Ph.D. Thesis, Technical University of Brno, Czech Republic, 2001.

10. Weiss, R.A.; Ashish, S.; Willis, C.L.; Pottick, L.A.; Polymer 1991, 32, 1867.

11. Lucas, E.F.; Soares, B.G.; Monteiro, E.; Caracterização de Polímeros. Determinação de Peso Molecular e Análise Térmica, e-papers: Rio de Janeiro, 2001.

Received: December 17, 2002

Published on the web: September 1, 2003

FAPESP helped in meeting the publication costs of this article. 